\title{
VALUATION OF SSH RESEARCH FOR A TRANSFORMATIVE EUROPEAN RESEARCH AGENDA - A FEW CLOSING WORDS
}

\section{KLAUS SCHUCH}

DOI: 10.22163/fteval.2019.387

\section{INTRODUCTION}


s called upon by the promoters of the Austrian Presidency of the EU Council Conference on 'Impact of Social Sciences and Humanities for a European Research Agenda - Valuation of SSH in mission-oriented research' it is time to re-load the notion of impact of Social Sciences and Humanities (SSH) and to shift away from the traditional pre-dominant defensive stance which SSH research often articulates in the discussion about the impact of research. Doubtlessly, most arguments raised by critical SSH researchers are relevant such as the too narrow focus on economically relevant technologies and innovation, but a defensive stance not accompanied by positive propositions would inevitably lead to a marginalised position which is sometimes already now met with suspicion from policy-makers, but also from fellow colleagues of the so called 'hard sciences'. Thus, instead to dwell on the embodiment of 'integrating' SSH into dominantly technologicallyminded projects too long, SSH researchers should shift the notion and the promotion to equally valuated contributions of SSH to transformative inter-disciplinary research with $\mathrm{SSH}$ at eye-level.

This also means to push forward SSH into a driver-seat in addressing grand challenges and in implementing mission-oriented research in Horizon Europe. The challenges are grand because they concern our societies and cultures. Challenges can and should not only be met by providing technological fixes, but by investigating their socio-economic and cultural embedding and structural fundaments and by aiming to identify solutions which address, reflect, reframe and eventually also challenge and change these underlying structures. By doing so, SSH research can provide disruptive contributions to break-up with traditional ways of doing things. The political economy in any grand challenge can become scrutinised, but it also needs to be addressed in calls launched under transformative research agendas. This is e.g. true for the political economy of climate change, or the political economy of transportation or of health research. The often raised differentiation between an instrumental understanding of SSH and a reflexive understanding of SSH is not helpful in this respect and has to be overcome in transformative research because both aspects ('instrumental' and 'reflexive') are important. Finally it also needs to be repeated, that innovation and value creation is not just the scope of R\&D, sales and marketing (or of Pillar 3 in Horizon Europe), but a social process with various social implications that can be addressed by fields such as anthropology, cultural studies, education, sociology or human and economic geography.

\section{A LOOK BACK ON SSH IN HORIZON 2020}

Around the peak of the financial and economic crisis around 10 years ago, national research budgets were cut due to financial constraints in several countries (Schögler and König, 2017; EUA, 2011;). These cuts were often also addressing the Social Sciences and Humanities (SSH) (Marimon et al, 2011, Papanagnou, 2011). Moreover, in the dawn of Horizon 2020, the EU's 8th Framework Programme for RTD, the role of Social Sciences and Humanities (SSH) within the world's largest competitive research programme was downgraded too (see König, 2019 in these proceedings). It was politically intended to mainstream SSH across the entire Horizon 2020 (European Parliament and Council, 2013) with the consequence of abolishing the specific sub-programme dedicated to SSH topics. These attempts, however, met resistance from parts of the SSH communities because 'mainstreaming' often results in 'ceding'. An Open Letter was signed by almost 26,000 people (Rammel et al., 2017), and some of the research ministers from the EU member states were successfully mobilised to express their concerns against this 'mainstreaming', which was frequently perceived as 'downsizing' of SSH (see König, 2019 in these proceedings).

The protest was relatively successful. SSH research is within Horizon 2020 now covered by six panels in the European Research Council, has a dedicated slot within the Societal Challenges Pillar of Horizon 2020 (however with a pitying marginal budget) and is more or less (with emphasis on 'less') sufficiently mainstreamed across the Societal Challenges Pillar.

Also the overall mind-set seems to have changed because the inclusion of SSH with a dedicated topical niche within the next edition of the European Framework Programme for Research and Innovation (in addition to its place in the ERC and the still valid mainstreaming approach) was politically almost not contested anymore. This mind-set change, however, does not materialise in a considerable larger SSH budget for its topical niche, but might rather be an indication of a more sober expectation management by R\&l policy makers in that sense, that technological fixes without proper consideration of human conditions are not sufficient for tackling grand challenges and inducing transformational changes.

The idea behind this observable mind-change seems to refer primarily to attributing an enhanced support or leverage function of SSH to a more 'society-ready' technological development, in order to avoid waste of re- 
sources and idle capacities. In this line of argument, the focus remains on the cooperation of SSH with technology-oriented disciplines rather than on strengthening genuine SSH topics in Horizon Europe, the EU's next European Framework Programme for RTD (2021-2027). The narrative about the potential leveraging function of SSH was already promoted in Horizon 2020 in line with the 'integration/mainstreaming' approach. In fact, and this should be appreciated, Horizon 2020 was a pioneer in this respect, while most national technology-oriented programmes still lack a clear commitment to include SSH research strategically, although one can frequently identify SSH related methods, RRI aspects, and claims of social challenges as well as impacts subcutaneously in industry-oriented applied R\&D programmes too as evidenced by a study about SSH aspects in projects funded by the Austrian Research Promotion Agency (Sturn and Schuch, 2018).

The popular narrative of the auxiliary function or contribution of SSH to technology-based innovation processes is often framed in the context of inter- and trans-disciplinary challenges (see Graf, 2019 in these proceedings). Especially trans-disciplinarity, which features outreach to and inclusion of non-academic stakeholders and of non-formalized knowledge, is a competence which is sometimes credulously assigned to SSH researchers because of their perceived proximity to social spheres. This cross-academic approach is strongly featured in the pillar "Global Challenges and Industrial Competitiveness" of Horizon Europe, which should 'encourage cross-disciplinary, cross-sectoral, cross-policy and cross-border collaboration in pursuit of the UN SDGs and the competitiveness of the Union's industries therein.' (European Commission, 2018; p. 17).

This understanding of the leverage function of SSH requires that SSH researchers are capable and professional in meeting and applying state of the art involvement tools. The contribution of SSH to more technological oriented projects and its peculiar value is basically perceived as a project steering and outreach competence, especially if issues of the normal course of life and/or the inclusion of non-academic audiences (e.g. stakeholders, users) are concerned. This understanding became a partially shared reality in many Horizon 2020 projects. In certain research fields (such as "Public Health and Sustainable Development") the use of transdisciplinary tools is daily business. Often social scientists are charged with engagement processes by applying a variety of process tools such as design-thinking, participatory technology development or multistakeholder workshops.

\section{FROM INSTRUMENTAL TO COMPREHENSIVE SSH CONTRIBUTIONS IN MISSION- ORIENTED RESEARCH}

Clearly, many SSH researchers regard this overall approach to treat SSH research as an auxiliary (or 'instrumental') resource for technological projects which address the grand challenges, often as an improper reduction of SSH. This view is not far-fetched, because the grand challenges are grand since they concern human societies and cultures, the ways how we humans interact with each other but also with our environment, how we produce and consume, how we construct meaning and judgement to our actions, and how we reproduce our societies and cultures but also how we change them and our behaviour. Before asking how SSH can mitigate the effort of technological adaptations to social conditions, needs and wants, thus contributing to an innovation race which continuously seems to pick up pace, SSH should also be employed to frame and analyse the wicked problems before a technological solutionism approach (Morozov, 2013) is taken. Unfortunately, calls for proposals seldom ask for this. Especially in Horizon 2020 the scope and the expected impacts of the topics called for, are usually very specifically described in detail and often more oriented towards an end (i.e. a specific output, solution or impact) than a proper problem analysis. Although it could be argued, for instance, that any topic addressed under Horizon 2020 (from "A" like agriculture, "B" like bio-economy, "C" like climate change to "Z" like zero-waste) would at least deserve a proper analysis of the political economy underlying these topics.

Instead, technological solutionism promises quick results and profits and is positively connoted with an attractive entrepreneurial 'hooray - let's go for it' image, which has undermined and captured research policy-making since more than 30 years and which led to the "holy duality" of research and innovation. The concept of "societal readiness levels' is fitting this auxiliary understanding of SSH to leverage the social acceptance of technologies. It should absolutely not be denied that SSH can be very useful in this respect. On the contrary, usage of novelty and accompanying market pervasion (which is the economic essence of innovation) is a social process with various social implications. Innovation research thus can be a subject of business economics, but also of anthropology, cultural studies, political sciences, sociology, economic and human geography and so forth.

Innovation is basically anything new that creates some form of value; and there is no value creation without some sort of uptake. Value can be an economic one but it should not be limited to it. Thinking about innovation should not be reduced to its technical substance, which is often associated with the notion of innovation per se, often in combination with economic value creation, which belittles the contribution of SSH (Bell, 2019 in these proceedings). In fact, these days we are more and more used to think about different types of innovation such as business-model innovations, organisational innovations, public sector innovations, and social innovations. And we know since the fundamental works of Schumpeter, that (some) innovations have the potential to transform the way we live and the things we do, socially and culturally as well as economically.

After some naive R\&I policy 'gold rush years', characterised by a simplistic understanding of the relationship between research and innovation as linear process in which research is expected to lead to ever higher Technology Readiness Levels (Bell, 2019), there is also increasing awareness that the idea of public support for 'research and innovation' should be to support the right innovations and not innovations per se. What "right" means depends on a plethora of views, principles and beliefs and should never be decided in isolation. The important thing here is to understand, that innovation is not only the business of business, but also the business of society. And as a business of society it also becomes a business of SSH research. Bell (2019) calls in this respect for a genuine and broad added-value of SSH for transformative research, starting with the "what if" question, constructing alternative scenarios and by considering also the non-material features of human existence. He furthermore claims that SSH can provide strong contributions to make transformations happen.

The orientation on grand challenges, energised by the 'missions concept' in Horizon Europe (Mazzucato, 2018) can be regarded as an indica- 
tion of the updated emphasis on the directionality of R\&l policies to tackle the 'right' issues (e.g. connected with sustainability and/or inclusiveness concerns) with the intention of selecting the adequately 'right' R\&I projects in service of society. The Lamy-Report (2017) stipulated the need to develop adequate impact oriented RTI policy designs and made the claim that SSH should also act as driver for some missions of the next Framework Programme for RYl (and as contributor to others). In line with this, the European Parliament (2017) argued for a broader and clearer definition of impact by raising awareness on societal, cultural and long-term impacts, while the Estonian EU Council Presidency (2017) urged in general for a more sophisticated and dynamic approach to impact assessment. These political claims (and others) were taken-up and addressed during the Austrian Council of the EU Presidency Conference on the 'Impact of SSH for a European Research Agenda - Valuation of SSH in mission-oriented research', which was organised by the author of this article in Vienna end of November 2018 (König, Nowotny and Schuch, 2019 in these proceedings; Reiter-Pazmandy, 2019 in these proceedings).

During the conference it became clear that there is widespread accord among the SSH communities that the impact of SSH research is more direct on society than from other research disciplines, although not necessarily more evident or tangible. This seems to be a basic contradiction, which should be solved to overcome disaccord and resistance. The impact of SSH research is more direct because the social subsystems 'Culture', 'State', and 'Market' are very often in the focus of SSH research. SSH researchers thus sometimes claim that they, by purpose, are closer to issues such as societal impacts, structuring impacts on policy-making and policies (i.e. political impact) as well as impacts on innovation and economy (see among others Flecha, Soler-Gallart, and Sordé, 2015; Brewer, 2013). For the sake of orientation, Reale, E. et al. (2017) provide a definition of scientific, social and political impact, stating that "SSH research generates scientific impact when it influences the production of further research outputs following new approaches for analysis or based on new results. Changes related to social impact affect the cultural, economic, and social life of individuals, organizations, and institutions. Political impact incorporates the contents of research into political decisions, and motivations and rationales for political action and priority setting."

\section{TRACING AND MEASURING IMPACT OF SSH RESEARCH}

Impact tracing, however, is a complex exercise, because it is contextspecific and there are different understandings of valuation narratives and theories of change of SSH research, which by themselves request thorough understanding of processes and methods in the phases of knowledge production (e.g. co-design and co-creation; inter- and transdisciplinary approaches; citizen science;), knowledge dissemination (e.g. tailor-made transfer mechanisms and formats; media engagement) and knowledge usage (e.g. social innovation; policy advice; evaluation and accompanying scientific research; research integrated road mapping; [public] service engineering etc.) with all their particular challenging aspects. Beck and Bonß (1989) even claimed that interpretation offers provided by social sciences are practically most successful, when the seemingly vanish without trace in the consciousness of everyday life and policy. What makes impact measurement of SSH research even more complex is the fact that standardised indicators of usage beyond the sci- entific impact dimension are missing. For instance, SSH research does hardly result in patent applications. So far, existing assessments of the social impact of RTI political interventions are often only contextual and specific as well as qualitative and anecdotal in nature (Van den Besselaar et al, 2018; Raua, Gogginsb and Fahyb, 2018; Barré, 2010).

Also the judgments on the value-for-society vary (Reale et al., 2017). Despite the fact that SSH scholarship is often committed to do research for the good of society, the interest of researchers is often not oriented towards producing usable results, but rather to raise awareness and influence society to create capabilities of self-understanding in different contexts (Reale et al., 2017; Benneworth, 2015; Nussbaum, 2010).

Social impact measurement, which - and this is important to note concerns all scientific disciplines and sciences - remains an unresolved issue in technical terms too. The complexity goes far beyond monetarised approaches such as SROI (Social Return on Investments) or SMEV ('Socially Modified Economic Valuation' approach). Tracing, assessment and measuring (centred on the core question 'What is the evidence for observed effects?') is not only complex but also exacerbated by metric problems (which apparently materialise at the level of indicators and data basis). Social impact assessments thus focus often more on processes than on results (e.g. engagement with business, government, the third sector, and the public via the media as a proxy for social impact) (Bastow, Dunleavy, Tinkler; 2014). Moreover, there is often a falsified equation of social impact with dissemination or transfer, to which most of the socalled alternative metrics (altmetrics) focus. In Horizon Europe, mostly process and output indicators will be applied to trace the societal impact and policy impact (Van den Besselaar et al., 2018).

Particular challenges for the development of appropriate indicators to measure societal impact include firstly, that the time taken to achieve the actual impact on society is longer than the achievement of concrete results; secondly, that the assignment of social changes is more difficult than the assignment of scientific references or economic attributes. And, thirdly, that the availability and comparability of data to track social and political impacts is severely limited. So far, however, the tracing, assessment and metric question of social and political impact seems to be more discussed and forwarded by the domains of research policy and evaluation research while most SSH researchers from academia have only partially adopted it as their own.

\section{CLOSING WORDS}

The five missions announced by the European Commission in summer 2019 do not indicate a big change. They all relate to important challenges, for which SSH can make contributions, but not in the driver seat. On the other hand, however, SSH research will also have to keep its promise in thousands of ways to find a new level of interaction with society. This refers to the claim made by König, Nowotny and Schuch, 2019 in these proceedings) as starting point for organising the Austrian Council of the EU Presidency conference on 'Impact of Social Sciences and Humanities for a European Research Agenda - Valuation of SSH in mission-oriented research', that 'transformative science must be transformative in a double sense: wanting to exert influence in society but also open to be influenced by society and its needs.'

Such an exercise is not easy and will demand a lot of efforts and creativity. There are for instance still several areas, where the relation of SSH to society is less expressed than one would assume. Such shortcomings 
can for instance be found with respect to citizen science or social innovation (Howaldt, 2019 in these proceedings; Anderson, Domanski and Howaldt, 2018; Howaldt et al. 2016), although we find a long tradition of action research which stimulated social action (Gustavsen, 2012), which, however, should not be equalized with social innovation.

These shortcomings, however, also have structural reasons, such as the comparatively low funding fondness towards SSH-driven citizen science projects. Also in the area of social innovation, one can hardly find material or immaterial professional structures within most higher education and non-university research organisations for supporting social innovation. Examples like the "6l research model" at the University of Deusto (Caro-Gonzalez, 2019 in these proceedings) or the Knowledge Transfer Centre for SSH in Austria (Russegger, 2019 in these proceedings) are still the exception and not the rule.

\section{LITERATURE}

Anderson, M. M., Domanski D. and Howaldt, J. (2018): Social Innovation as a chance and a challenge for Higher Education Institutions. In J. Howaldt, C. Kaletka, A. Schröder and M. Zirngiebl (Ed.), Atlas of Social Innovation. New Practices for a Better Future (pp. 50-53). Dortmund: Sozialforschungsstelle, TU Dortmund University.

Bastow, S., Dunleavy, P. and Tinkler, J. (2014): The Impact of the Social Sciences. Los Angeles-London-New Dehli-Singapore-Washington DC: SAGE.

Beck, U. / Bonß, W. (Hrsg), 1989: Weder Sozialtechnologie noch Aufklärung? Analysen zur Verwendung sozialwissenschaftlichen Wissens. Frankfurt: Suhrkamp.

Bell, J. S. (2019): The importance of SSH research in Horizon Europe. Fteval Journal for Research and Technology Policy Evaluation, Issue 48, June 2019, pp. 48-51. D0I: 10.22163/fteval.2019.366

Benneworth, P. (2015): Tracing How Arts and Humanities Research Translates, Circulates and Consolidates in Society. How Have scholars Been Reacting to Diverse Impact and Public Value Agendas? Arts and Humanities in Higher Education, 14/1: pp. 45-60.

Brewer, J. (2013): The Public Value of Social Sciences. An Interpretative Essay. Bloomsbury.

Caro-Gonzalez, A. (2019): The "6l Research Model": Evolution of an Innovative Institutional STI Policy Framework at the University of Deusto. Fteval Journal for Research and Technology Policy Evaluation, Issue 48, June 2019, pp. 104-112. DOI: 10.22163/fteval.2019.376.

Estonian Presidency of the Council of the EU (2017): Tallinn Call for Action 2017. Seize the opportunity now: research and innovation matter for the future of Europe. Statement of the Estonian Presidency of the Council of the EU.

EUA (2011): Impact of the economic crisis on European universities. European University Association, January 2011.
European Commission (2018): Proposal for a Regulation of the European Parliament and of the Council Establishing Horizon Europe (COM(2018) 435 final, 2018/0224 (COD)), 17 (URL: https://ec.europa.eu/commission/ sites/beta-political/files/budget-may2018-horizon-europe-regulation_ en.pdf, accessed on 31.10.2018.

European Parliament (2017): Report on the assessment of Horizon 2020 implementation in view of its interim evaluation and the Framework Programme 9 proposal (2016/2147(INI)).

European Parliament and Council (2013). Regulation (EU) No 1291/2013 of 11 December 2013 establishing Horizon 2020, Annex I, 121 (URL: https://eur-lex.europa.eu/LexUriServ/LexUriServ.do?uri=0J:L:2013:347:010 4:0173:EN:PDF, accessed on 31.10.2018.

Flecha, R., Soler-Gallart, M. and Sordé, T. (2015): Social Impact: Europe Must Fund Social Science. Nature, 528: 193. Doi: 10.1038/528193d.

Graf, J. (2019): Bringing Concepts Together: Interdisciplinarity, Transdisciplinarity and SSH Integration. Fteval Journal for Research and Technology Policy Evaluation, Issue 48, June 2019, pp. 32-35. D0I: 10.22163/ fteval.2019.364

Gustavsen, B. (2012). Social Innovation and Action Research. In H.-W. Franz, J. Hochgerner and J. Howaldt (Ed.), Challenge social innovation: Potentials for business, social entrepreneurship, welfare and civil society (pp. 353-366). Berlin, New York: Springer.

Howaldt, J. (2019): New Pathways to Social Change - Creating Impact through Social Innovation Research. Fteval Journal for Research and Technology Policy Evaluation, Issue 48, June 2019, pp. 36-47. D0I: 10.22163/fteval.2019.365

Howaldt, J., Kaletka, C., Schröder, A., Rehfeld, D. and Terstriep, J. (2016). Mapping the World of Social Innovation. Key Results of a Comparative Analysis of 1.005 Social Innovation Initiatives at a Glance. SI-Drive Project. https://www.si-drive.eu/?p=2283; accessed on 30 June 2019.

König, T. (2019): SSH-Imapct Pathways and SSH-Integration in EU Research Framework Programmes. Impact re-loaded. Fteval Journal for Research and Technology Policy Evaluation, Issue 48, June 2019, pp. 7-8. DOI: 10.22163/fteval.2019.362

König, T., Nowotny, H. and Schuch, K. (2019): Impact re-loaded. Fteval Journal for Research and Technology Policy Evaluation, Issue 48, June 2019, pp. 7-8. DOl: 10.22163/fteval.2019.361

Lamy, P. et al. (2017): Lab, Fab, App. Investing in the European future we want. Report of the independent High Level Group on maximising the Impact of EU Research and Innovation Programmes. European Commission (the so called 'Lamy-Report').

Marimon, R., Guardiancich, I., Mariathasan, M. and Rossi, E. (2011): Survey on Research Funding for the Social Sciences in Europe. European University Institute. 
Mazzucato, M. (2018). Mission-Oriented Research and Innovation in the European Union. Retrieved October 18, 2018 from: https://ec.europa.eu/ info/sites/info/files/mazzucato_report_2018.pdf.

Morozov, E. (2013): To Save Everything, Click Here: Technology, Solutionism, and the Urge to Fix Problems that Don't Exist, London.

Nussbaum, M. (2010): Not for Profit. Why Democracy Needs the Humanities. Princeton: Princeton University Press.

Papanagnou, G. (ed) (2011): Social Science and Policy Challenges. Democracy, Values and Capacities. UNESCO.

Rammel, S., Hoffmann, A. and Halbmayr, B. (2017): ERA Thematic Dossier on Social Sciences and Humanities (SSH) in Horizon 2020. FFG: Austrian Research Promotion Agency.

Raua, H., Gogginsb, G. and Fahyb, F (2018): Form invisibility to impact: Recognising the scientific and societal relevance of interdisciplinary sustainability research. Research Policy, 47, pp 266-276. D0I: 10.1016/j. respol.2017.11.005.

Reale, E. et al. (2017): A review of literature on evaluating the scientific, social and political impact of social sciences and humanities research. Research Evaluation 2017, 1-11, doi: 10.1093/reseval/rvx025.

Reiter-Pázmándy, M. (2019): Foreword. Fteval Journal for Research and Technology Policy Evaluation, Issue 48, June 2019, pp. 5-6. D0I: 10.22163/fteval.2019.360.

Russegger, G. (2019): SSHA-Driven Knowledge Transfer Within the Third Mission of Universities. Foreword. Fteval Journal for Research and Technology Policy Evaluation, Issue 48, June 2019, pp. 61-64. D0I: 10.22163/ fteval.2019.369

Schögler, R. and König, T. (2017): Thematic Research Funding in the European Union: What is Expected from Social-Scientific Knowledgemaking? Serendipities 2.2017 (1): 107-130 | D0I: 10.25364/11.2:2017.1.7

Sturn, D. and Schuch, K. (2018): Geistes-, sozial- und kulturwissenschaftliche Aspekte in FFG geförderten Innovationen. Report for the Austrian Research Promotion Agency (not published).

Van den Besselaar, P., Flecha, R. and Radauer, A. (2018): Monitoring the Impact of EU Framework Programmes. Expert Report. Publications Office of the European Union: Luxembourg.

\section{AUTHOR}

\section{KLAUS SCHUCH}

Zentrum für Soziale Innovation GmbH - Centre for Social Innovation (ZSI) Linke Wienzeile 246, Vienna, 1150 (Austria)

E: $\underline{\text { schuch@zsi.at }}$ 